\title{
Comparing the Effects of Choline with Clozapine and Fluoxetine for Improving Cognitive Behavior in Rats
}

M. Iqbal Ahsan, Fareeda Islam, Farah Asad, Fatima Rizvi, Sana Imran, Jawed lqbal Jinnah Medical and Dental College, Karachi, Pakistan.

\begin{abstract}
Background: Cognitive behavior therapy is an important treatment for various psychiatric and psychological problems. Different psychotherapeutic treatments are used for improvement in patients. The study aimed to compare Clozapine and Fluoxetine with Choline on the progress of cognition and cognitive behavior in rats.
\end{abstract}

\begin{abstract}
Methods: This experimental study was conducted in the pharmacology department of Karachi University on locally bred male albino rats $(n=24)$. These were divided into four treatment groups (Saline, Fluoxetine, Clozapine, and Choline) and measured the output at the $1^{\text {st }}, 3^{\text {rd }}, 5^{\text {th }}$, and $7^{\text {th }}$ weeks. Familiar and Novel object recognition test and Passive avoidance test was used to observe learning and memory as well as the mechanism of cognition. One way-ANOVA and post-hoc analysis was done between groups. The $p$-value $<0.05$ and $<0.001$ were considered statistically significant and highly significant respectively.
\end{abstract}

Results: The comparative mean preference index percentage between saline, choline, clozapine, and fluoxetine at week one was non-significant ( $p>0.05)$ in the Novel and Familiar Object Recognition test. However, at week three it was highest for Fluoxetine (58.15 \pm 3.35 ) compared to Choline, Clozapine and Saline for the novel object. However, in Familiar objects, it was found highest for Clozapine (58.88 \pm 3.05$)$ ( $p<0.05)$. Furthermore, the mean step-through latency time of the Passive Avoidance test was significant $(p<0.05)$ at weeks three, five and seven. It was highest for choline (92.5 \pm 1.36 ) than fluoxetine and clozapine.

Conclusion: Fluoxetine has a significant effect $(p<0.001)$ on memory and learning compared to Clozapine. Clozapine and choline showed statistically same results on cognitive behavior.

Keywords: Cognitive Behavior; Choline; Clozapine; Fluoxetine; Effect; Compare.

\section{Corresponding Author: \\ Dr. Farah Asad}

Jinnah Medical and Dental College, Karachi, Pakistan.

Email: asad-farah@hotmail.com

https://doi.org/10.36283/PJMD1 1-1/006

How to cite: Ahsan MI, Islam F, Asad F, Rizvi F, Imran S, labal J. Comparing the Effects of Choline with Clozapine and Fluoxetine for Improving Cognitive Behavior in Rats. Pak J Med Dent. 2022;11(1): 32-37. doi: 10.36283/PJMD11-1/006

\section{INTRODUCTION}

Cognitive behavioral therapy (CBT) modulates the patient's thoughts and feelings, which create a positive impact on their behavior' ${ }^{1}$. Cognitive thera- py is the kind of CBT, which targeted on recognizing and distinguishing thoughts, emotional reactions, and behavior pattern ${ }^{2}$. It is explained the reasoning, cognition, problem-solving, making tasks to com- 
plete, working memory, planning, and accordingly allowing the thoughts and actions in fulfilling the target of behavioral goals ${ }^{3}$. In different behavioral and emotional attitudes, the $\mathrm{ACH}$, dopamine, and serotonin receptors are involved ${ }^{4}$. Neuroleptics have a blocking action on 5HT2A and Dopamine receptors, atypical antipsychotic drugs were more effective than other one ${ }^{5}$. Clozapine is used for the treatment of Psychosis by blocking Dopamine D4, $\mathrm{H} 1$ and alphal adrenergic and muscarinic receptors. It also acts as a serotonin antagonist on $5-\mathrm{HT} 2 \mathrm{~A} / 2 \mathrm{C}$ subtypes of receptors ${ }^{6,7}$. The adverse effects of clozapine are orthostatic hypotension, tachycardia, fever, seizures, weight gain, metabolic syndrome, gestational syndrome, sedation, ECG changes, fatigue, leukopenia, and agranulocyto$\mathrm{sis}^{8}$. Fluoxetine is SSRI and is used for the treatment of depressed patients. Their half-life is 1-3 days in the acute dose and 4-6 days in the chronic dose and side effects are erectile dysfunction, nausea, anorgasmia, headache, weight loss, drowsiness, tremors, diarrhea, and photosensitivity?.

In different physiological functions, choline is a basic nutrient. Its average intake in an adult human is $700-1200 \mathrm{mg} /$ day. Human milk as well as the colostrum is the choline-rich source. Choline synthesis occurs in neurons from dietary products and de novo synthesis. It is the precursor of acetylcholine, sphingomyelin, phosphatidylcholine and methyl donor betaine that helps in the conversion of homocysteine to methionine. Adequate choline in the brain protects from aging, dementia and Alzheimer's disease ${ }^{10}$. They are found in food mostly and have an important and basic role in cells' normal functioning ${ }^{11}$. This study aimed to measure the cognitive behavior modulation by choline and compared it with Fluoxetine and clozapine.

\section{METHODS}

Total $n=24$ male albino rats with 180-200gms, randomly divided into four treated groups (six in each group): Saline (Control) $(n=6)$, Fluoxetine $(n=6)$, clozapine $(n=6)$ and Choline $(n=6)$ respectively and all were examined at first, third, fifth and seventh week. We assessed cognitive modulation by behavioral parameters. The pair of rats caged before one week of the experiment under a normal day/night cycle with room temperature. This study was conducted after ethical approval from BASR (BASR No/ 0304 Pharm) in the pharmacology department of Karachi University. Normal standard diet and free access to water provided to experimental rats. In the Saline group (Control); rats were given $2.0 \mathrm{ml} / \mathrm{kg} /$ day of normal saline for seven days. In Fluoxetine Group rats were treated with $2 \mathrm{mg}$, $5 \mathrm{mg}$ and $8 \mathrm{mg}$ suspension / $\mathrm{Kg} /$ day with the feeding tube. The stock solution was prepared by powdered fluoxetine by adding in $10 \mathrm{ml} 0.9 \% \mathrm{Nacl}$ to make $1 \mathrm{ml} / \mathrm{ml}$ suspension. In the Clozapine Group dose of
$2 \mathrm{mg}$, $5 \mathrm{mg}$ and $8 \mathrm{mg} / \mathrm{Kg} /$ day suspension were made by powdered clozapine in $0.1 \mathrm{~N} \mathrm{HCL}$ of 5.5 adjusted $\mathrm{PH}$ and was administered by a feeding tube to rats ${ }^{12}$. Lastly in the Choline Group, the choline bitartrate tablet powder in aqueous solution form, $52 \mathrm{mg} / \mathrm{Kg} /$ day dose were given to rats through the oral route as the volume of $0.2 \mathrm{ml} / 150 \mathrm{grm}$ body weight. That dose was equal to the recommended dose of adult humans $(500 \mathrm{mg} /$ day/60/kg body weight) ${ }^{13}$.

The percentage of preference index was measured in the Familiar and Novel object recognition test. A preference index above $50 \%$ is said to be a modulation in the cognition process. The test framework consists of a gray painted wooden box had two identical objects. Both were filled with white cemented material to make it heavy and rats were unable to move it easily. To examine the panic aggravated test, we used the Passive avoidance test to evaluate the learning and memory by giving a foot shock in a dark compartment, rats stayed in a white environment due to recall memory. Thus, this interval to enter the dark compartment is a passive avoidance test. Data was entered and analyzed for correct and incorrect entry by using SPSS version 20. To measure the Novel and Familiar object recognition test, the mean preference index percentage was compared for familiar and novel object recognition between Saline and Choline with Fluoxetine and Clozapine at first, third, fifth, and the seventh week by using One way-ANOVA. The post-hoc analysis was measured by Tukey's test among the treated groups. The $p$-value $<0.05$ and $<0.001$ were considered significant and highly significant respectively.

\section{RESULTS}

The comparison of preference index $\%$ of albino rats $(n=24)$ among treated groups was found non-significant ( $p$-value >0.05) at week first and third in the Novel and Familiar object recognition test. In Novel objection rejection, the preference index \% at week five was 62.75 for choline, 58.15 for fluoxetine, 56.28 for saline, and 50.88 for clozapine. At week seven highly significant differences ( $p$-value $<0.001$ ) were found between the treated groups moreover, it was found that the preference index \% was highest in fluoxetine that is 64.86 then choline 57.97 after that clozapine 57.97 and lastly for saline 44.99. An increased in step-through latency means learning improvement, a component of cognition.

However, in familiar objection recognition, it was observed that preference index \% of Familiar object recognition on post-hoc, the significant difference ( $p$-value>0.05) at week five and seven. At week five the difference was found among Saline and Choline (43.65:37.12), Choline and Clozapine (37.12: 55.88), and Choline and fluoxetine (37.12: 
40.57). At week seven, it was highest for Clozapine that is 58.88 followed by Saline 53.55, Fluoxetine 41.78 then Choline 40.34. On post hoc analysis significant difference ( $p$-valve $<0.05$ ) was found among treated groups. As depicted in Table 1. It is purely a learning activity based on improvement in recognition and memory.

Table 2 showed the mean step-through latency time (seconds) among treated groups. At week one non-significant differences ( $p$-value>0.05) were found. At week three significant difference was observed between Saline and Fluoxetine (58.67 vs
67.00; $p$-value 0.05), Saline and Choline (58.67 vs 67.00; $p$-value <0.05) and Saline and Clozapine (58.67 vs 67.00; $p$-value<0.05). However, at week five mean latency times were highest for Choline (92.67) followed by Clozapine (89.00) than Fluoxetine (80.67) least for saline (61.67) moreover highly significant difference ( $p$-value $<0.001$ ) was found between Saline and Choline with Clozapine and Fluoxetine. At week seven the highly significant difference ( $p$-value<0.001) was found, it was highest for Choline than Fluoxetine followed by Clozapine, and lastly for Saline.

Table 1: Comparing preference index of treated groups in novel and familiar object recognition test.

\begin{tabular}{|c|c|c|c|c|}
\hline \multicolumn{5}{|c|}{ Groups } \\
\hline Weeks & $\begin{array}{c}\text { Saline } \\
\text { Mean } \pm \text { SEM } \\
(n=6)\end{array}$ & $\begin{array}{c}\text { Choline } \\
\text { Mean } \pm \text { SEM } \\
(n=6)\end{array}$ & $\begin{array}{c}\text { Clozapine } \\
\text { Mean } \pm \text { SEM } \\
(n=6)\end{array}$ & $\begin{array}{c}\text { Fluoxetine } \\
\text { Mean } \pm \text { SEM } \\
(n=6)\end{array}$ \\
\hline \multicolumn{5}{|c|}{ Novel Object Recognition Test } \\
\hline $1^{\text {st }}$ & $51.7 \pm 1.87$ & $54.1 \pm 2.94$ & $45.67 \pm 3.98$ & $53.93 \pm 4.78$ \\
\hline $3^{\text {rd }}$ & $50.88 \pm 2.38$ & $52.75 \pm 1.69$ & $51.32 \pm 2.75$ & $55.08 \pm 3.36$ \\
\hline $5^{\text {th }}$ & $56.28 \pm 2.63$ & $62.75 \pm 2.28^{* *}$ & $50.88 \pm 4.29+*$ & $58.15 \pm 3.35^{+}$ \\
\hline $7^{\text {th }}$ & $44.99 \pm 1.99$ & $57.97 \pm 1.75^{* *}$ & $52.8 .1 \pm 3.07^{++}$ & $64.86 \pm 0.99 * *$ \\
\hline \multicolumn{5}{|c|}{ Familiar Object Recognition Test } \\
\hline $1^{\text {st }}$ & $50.27 \pm 1.94$ & $47.28 \pm 3.27$ & $53.88 \pm 3.89$ & $46.03 \pm 4.77$ \\
\hline $3^{\text {rd }}$ & $49.00 \pm 1.94$ & $49.37 \pm 3.60$ & $47.28 \pm 3.27$ & $53.88 \pm 3.89$ \\
\hline $5^{\text {th }}$ & $43.65 \pm 2.62$ & $37.12 \pm 0.96^{*+}$ & $55.88 \pm 4.24$ & $40.57 \pm 1.80$ \\
\hline $7^{\text {th }}$ & $50.27 \pm 1.94$ & $40.34 \pm 1.23^{*+}$ & $58.88 \pm 3.05$ & $41.78 \pm 5.07$ \\
\hline
\end{tabular}

${ }^{*} p<0.05$ as compared to saline ${ }^{* *} p<0.001$ as compared to saline $+p<0.05$ as choline versus clozapine $++p<0.001$ as choline versus clozapine $+p<0.05$ as choline versus fluoxetine $++p<0.001$ as choline versus fluoxetine.

Table 2: Comparison of mean latency time of treated groups in passive avoidance test.

\begin{tabular}{|c|c|c|c|c|}
\hline Weeks & $\begin{array}{c}\text { Saline } \\
\text { Mean } \pm \text { SEM } \\
n=6\end{array}$ & $\begin{array}{c}\text { Choline } \\
\text { Mean } \pm \text { SEM } \\
n=6\end{array}$ & $\begin{array}{c}\text { Clozapine } \\
\text { Mean } \pm \text { SEM } \\
n=6\end{array}$ & $\begin{array}{c}\text { Fluoxetine } \\
\text { Mean } \pm \text { SEM } \\
n=6\end{array}$ \\
\hline \multicolumn{5}{|c|}{ Mean Latency Time (sec) } \\
\hline $1^{\text {st }}$ & $10.16 \pm 0.45$ & $10.83 \pm 0.49$ & $9.16 \pm 0.49$ & $9.33 \pm 0.60$ \\
\hline 3 rd & $10.8 \pm 0.69$ & $10.5 \pm 0.53$ & $9.20 \pm 0.67$ & $10.80 \pm 0.42$ \\
\hline $5^{\text {th }}$ & $10.8 \pm 0.33$ & $6.5 \pm 0.33^{* *}$ & $6.00 \pm 0.45^{* *}$ & $11 \pm 0.51^{++}$ \\
\hline $7^{\text {th }}$ & $11.33 \pm 0.57$ & $4.00 \pm 0.33^{* *}$ & $5.16 \pm 0.45^{* *}$ & $11.8 \pm 0.58^{++}$ \\
\hline
\end{tabular}

${ }^{*} P<0.05$ as compared to saline, ${ }^{* *} P<0.001$ as compared to saline, $+P<0.05$ as choline versus clozapine, $++P<0.001$ as choline versus clozapine, $++P<0.001$ as choline versus Fluoxetine, $+P<0.05$ as choline versus Fluoxetine 
Ahsan et al.

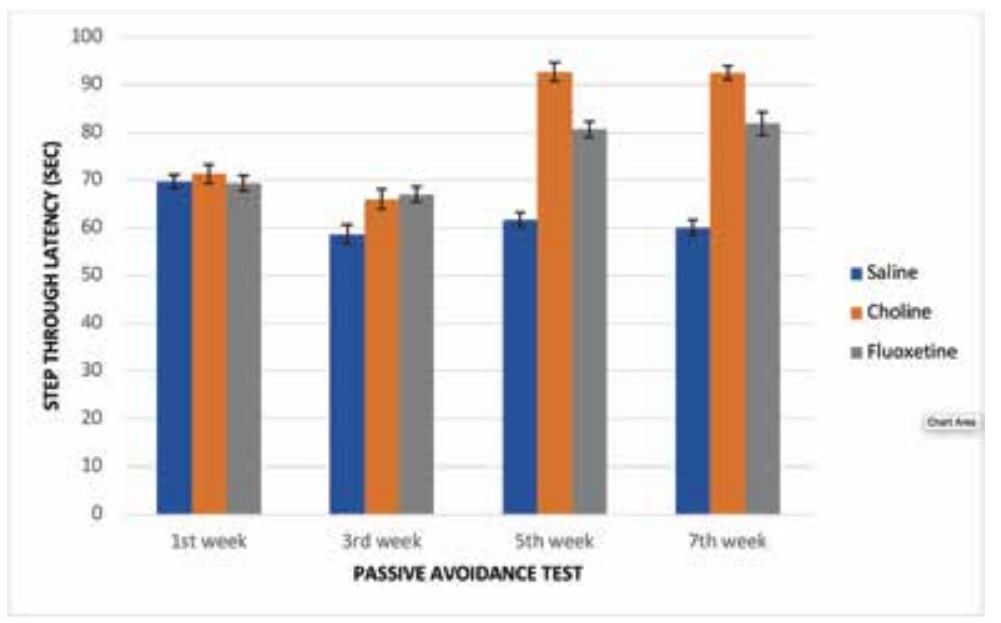

Figure 1: Comparison of Mean Latency Time (Step through latency) for Choline with Saline (control) and Fluoxetine Groups in Passive Avoidance Test.

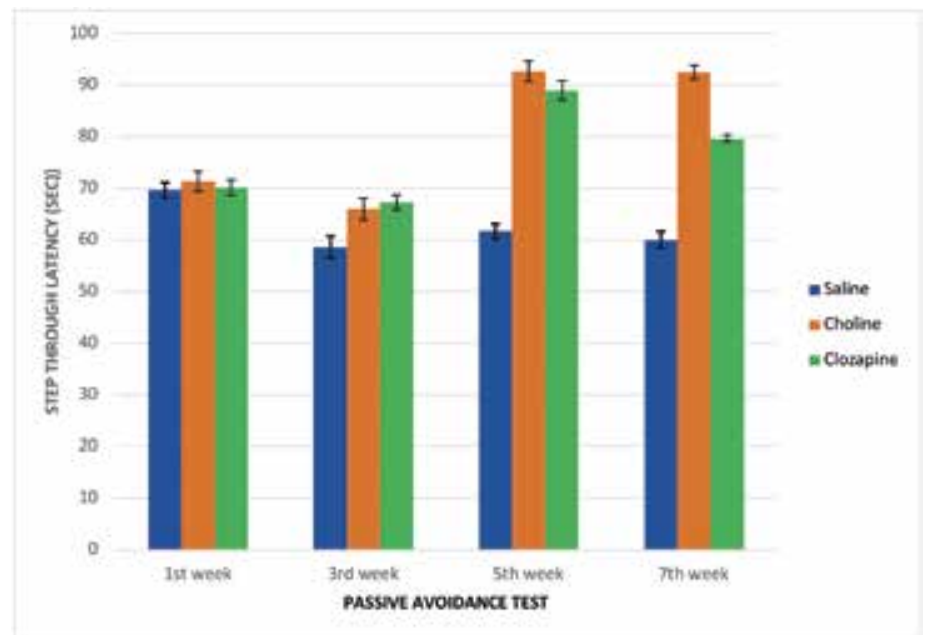

Figure: 2 Comparison of Mean Latency Time (Step through latency) for Choline with Saline (control) and Clozapine Groups in Passive Avoidance Test.

\section{DISCUSSION}

Cognitive behavior modulation is always targeted by research in diseases like anxiety, psychosis, drug abuse, and rheumatic diseases. In this study, a comparison between choline with fluoxetine an antidepressant drug, and antipsychotic agent a Clozapine for behavior modifications. The outcome showed that the clozapine and fluoxetine were significant effects as same as choline ${ }^{14}$.

The number of experimental tools in animal model learning, memory, recognition, can measure cognition behavior modulation and behaviors are important parameters used to measure the behavior modulation ${ }^{15}$. Passive avoidance retention test used to assess memory function in which animal exposed to the conditioned environment through lit to dark session. In the conditioned environment, the subjects received the foot shock after that the animal was placed in a safe area, door closed. The light was turned on; 2-3 minutes for adaptation then the light was off and animals were free to escape in dark area. Now step-through latency was recorded. Passive avoidance retention test showed the mean latency time was highest from week one to week three for choline and clozapine, moreover, fluoxetine showed significantly raised after week seven and least for saline. This test depends on hippocampal and amygdala ${ }^{16}$ which measured the long-term emotional memory up to 24 hours based on contextual fear conditioning and instrumental learning ${ }^{17}$.

The passive avoidance test results of the fluoxetine group showed increases in retention time from week five to seven, these results are in line with the current study who reported that fluoxetine raised fear distinction and recovery after training ${ }^{18}$. Another study explained that there are numerous mechanisms involved such as hippocampal remodeling ${ }^{19}$, 
increase in mPFC activity for recovery of remote memories in retrieval ${ }^{20}$.

Atypical antipsychotics had shown multiple receptor affinities ${ }^{21}$. D4, histamine and muscarinic receptors blocker activity. D4 receptors present in hippocampal and prefrontal cortex areas are important for cognitive process ${ }^{22}$. Another study showed that cognition is also enhanced by serotonin receptors (5HT2A) as a partial agonist activity ${ }^{23}$. One more study explained that 5HT2A receptor blocking the activity of ADP's due to partial agonist receptor activity of clozapine on Ml also improved learning and memory ${ }^{24}$. The choline sufficiency or depletion is related to aspects of behavior, learning, cognition, and memory performance ${ }^{25}$. Another study reported that raised choline release in the hippocampus and frontal cortex is related to an increase in locomotor activity in rats $^{26}$. All these effects of choline are related to modulation of histone and DNA methylation in the brain for encoding of protein through altered gene expression which is important for learning and memory process that is an epigenomic mode of action ${ }^{27}$.

However, a further explanation was considered by using the parameter of the Familiar and Novel objection recognition test in this study. Recognition means the study subjects aware that the stimulus has been experienced previously. It is based on memory and the required list of cognition operations like discrimination, comparison, perception, and identification. This is depending on post-experience. The recognition task is divided into two, one is objection recognition and the other is location recognition (spatial memory). Recognition memory is based on the general principle of matching an experience. In this study, two types of recognition were measured Familiar and Novel. The preference index of $50 \%$ indicated the Novel Object preference whereas the preference index of less than $50 \%$ indicated the Familial Object preference; while the $50 \%$ preference index represented no preference. Two identical Familial objects (A1 and A2) and a new Novel Object $B$, both filled with cement to make it heavy. This test has three stages as habituation, training, and test. On day one, the rats were exposed to a specific area for 10 minutes for familiarization. After 24 hours, the subjects were exposed to object A1 and A2 for 10 minutes. After that objects were removed from the box (training stage). Now for 20 minutes, the rats were exposed to a recognition box with novel object $B$ for 3 minutes. The parameters monitored during the test phase included the sniffing time for Novel and Familial object ${ }^{28}$.

The outcome of Novel recognition showed that the highest preference index was noted in the choline group from baseline (54\%) to week five (58\%). Besides these results, fluoxetine showed the highest index (64\%) at week seven. In the clozapine group, it was decreased as compared to other groups, these results are in line with another study that stated that choline modified the VAchT vesicular transporter that modulates object recognition memory ${ }^{29}$. In this study, clozapine showed a higher index for novel objection instead of familiar as compared to saline. About clozapine, it was 51.3\% significantly decreased to 50.88 as compared to choline it was $62.7 \%$ but still more than $50 \%$. This showed that choline increased recognition memory than clozapine depending on learning and past experiences. These results agree with another study that reported that clozapine has a protected effect on long-term memory produced by ketamine and recommended adjuvant use of both drugs improved cognition function. Other studies reported that acetylcholine has played a key role in motor function and cognition specifically attention, memory, and learning domains ${ }^{30}$. There are several molecular targets identified that include dopamine receptors in the prefrontal cortex, nicotinic and muscarinic acetylcholine receptors, the glutamatergic excitatory synapse various serotonin receptor, and the $r$ aminobutyric acid (GABA). These targets are studied for drug development aimed at enhancing cognition.

\section{CONCLUSION}

The study compared the cognitive behavior of the choline with fluoxetine and clozapine groups; however, the fluoxetine showed a positive effect on behavior. The outcome of clozapine effect on learning and memory was the same as choline used as a gold standard.

\section{ACKNOWLEDGEMENTS}

The authors are thankful to the Pharmacology Department of Karachi University.

\section{CONFLICT OF INTEREST}

The authors declare no conflict of interest.

\section{ETHICS APPROVAL}

Ethical approval was taken by the BASR committee of Karachi University (BASR No/ 0304 Pharm).

\section{AUTHORS' CONTRIBUTION}

MIA had conceived the idea and done the testing; $\mathrm{FI}$ did critical review and editing; FA did the manuscript writing; FR did statistics; SI did a literature review and $\mathrm{Jl}$ performed the data collection.

\section{REFERENCES}

1. Friedman ES, Koenig AM, Thase ME. Cognitive and behavioral therapies. InThe medical basis of psychiatry 2016. Springer, New York, NY, pp. 781-798. doi: 10.1007/978-1-4939-2528-5_35

2. Thapar A, Pine DS, Leckman JF, Scott S, Snowling MJ, Taylor EA, editors. Rutter's child and adolescent psychiatry. John Wiley \& Sons; 2017, p.5.

3. Braver TS, Barch DM. A theory of cognitive control, aging cognition, and neuromodulation. Neurosci 
Biobehav Rev. 2002;26(7):809-817. doi: 10.1016/ S0149-7634(02)00067-2

4. Hegazy HG, Ali EH. Modulation of monoamines and amino-acids neurotransmitters in cerebral cortex and hippocampus of female senile rats by ginger and lipoic acid. Afr J Pharm Pharmacol. 2011;5(8):1080-1085.

5. Grayson B, Idris NF, Neill JC. Atypical antipsychotics attenuate a sub-chronic PCP-induced cognitive deficit in the novel object recognition task in the rat. Behav Brain Res. 2007;184(1):31-38. doi: 10.1016/j. bbr.2007.06.012

6. Olton DS. Shock-motivated avoidance and the analysis of behavior. Psychol Bull. 1973;79(4):243-25 1. doi: 10.1037/h0033902

7. Baldessarini RJ, Frankenburg FR. Clozapine: a novel antipsychotic agent. N Engl J Med. 1991;324(11):746-754. doi: 10.1056/NEJM199103143241107

8. Merrill DB, Dec GW, Goff DC. Adverse cardiac effects associated with clozapine. J Clin Psychopharmacol. 2005;25(1):32-41. doi: 10.1097/01.jcp.00 $00150217.51433 .9 f$

9. Wenthur CJ, Bennett MR, Lindsley CW. Classics in chemical neuroscience: fluoxetine (Prozac). ACS Chem Neurosci. 2014;5(1):14-23. doi: 10.1021/ cn400186j

10. Amenta F, Parnetti L, Gallai V, Wallin A. Treatment of cognitive dysfunction associated with Alzheimer's disease with cholinergic precursors. Ineffective treatments or inappropriate approaches? Mech Ageing Dev. 2001;122(16):2025-2040. doi: 10.1016/S0047-6374(01)00310-4

11. Zeisel SH. Dietary choline: biochemistry, physiology, and pharmacology. Annu Rev Nutr. 1981;1(1):95-121. doi: 10.1146/annurev.nu.01.0701 81.000523

12. Batool FA, Saify ZS, Haleem MA, Haleem DJ. Neurochemical and extra pyramidal effects of atypical neuroleptic clozapine in rats. Pak J Pharm Sci. 2000;13(1):47-55.

13. Zeisel SH, Da Costa KA. Choline: an essential nutrient for public health. Nutr Rev. 2009;67(11):615-623. doi: 10.1111/j.1753- 4887.2009.00246.x

14. Hassett AL, Gevirtz RN. Nonpharmacologic treatment for fibromyalgia: patient education, cognitive-behavioral therapy, relaxation techniques, and complementary and alternative medicine. Rheum Dis Clin. 2009;35(2):393-407. doi: 10.1016/j.rdc. 2009.05.003

15. Izquierdo I, Barros DM, e Souza TM, de Souza MM, Izquierdo LA, Medina JH. Mechanisms for memory types differ. Nature. 1998;393(6686):635-636. doi: 10.1038/31371

16. Holland PC, Bouton ME. Hippocampus and context in classical conditioning. Curr Opin Neurobiol. 1999:9(2):195-202. doi: 10.1016/S0959-4388 (99)80027-0

17. Phillips RG, LeDoux JE. Lesions of the fornix but not the entorhinal or perirhinal cortex interfere with contextual fear conditioning. J Neurosci. 1995; 15(7):5308-5315. doi: 10.1523/JNEUROSCl

18. Pedraza LK, Sierra RO, Giachero M, Nunes-Souza
W, Lotz FN, de Oliveira Alvares L. Chronic fluoxetine prevents fear memory generalization and enhances subsequent extinction by remodeling hippocampal dendritic spines and slowing down systems consolidation. Transl Psychiatry. 2019;9(1):1-12. doi: 10.1038/s41398-019-0371-3

19. Bessa JM, Ferreira D, Melo I, Marques F, Cerqueira JJ, Palha JA, et al. The mood-improving actions of antidepressants do not depend on neurogenesis but are associated with neuronal remodeling. Mol Psychiatry. 2009;14(8):764-773. doi: 10.1038/mp. 2008.119

20. Bontempi B, Laurent-Demir C, Destrade C, Jaffard R. Time-dependent reorganization of brain circuitry underlying long-term memory storage. Nature. 1999;400(6745):671-675. doi: 10.1038/23270 21. Naheed M, Green B. Focus on clozapine. Current medical research and opinion. 2001;17(3):223-239. doi: 10.1 185/0300799039117069 22. Mrzljak L, Bergson C, Pappy M, Huff R, Levenson R, Goldman-Rakic PS. Localization of dopamine D4 receptors in GABAergic neurons of the primate brain. Nature. 1996;381 (6579):245-248. doi: 10.1038/ $381245 a 0$

23. Newman-Tancredi A, Gavaudan S, Conte C, Chaput C, Touzard M, Verrièle L, et al. Agonist and antagonist actions of antipsychotic agents at 5-HT1 A receptors: a [35S] GTPYS binding study. Eur J Pharmacol. 1998;355(2-3):245-256. doi: 10.1016/ S0014-2999(98)00483-X

24. Bymaster FP, Felder C, Ahmed S, McKinzie D. Muscarinic receptors as a target for drugs treating schizophrenia. Curr Drug Targets CNS Neurol Disord. 2002; 1 (2):163-181. doi: 10.2174/1568007024606249

25. Baumel BS, Doraiswamy PM, Sabbagh $M$, Wurtman R. Potential Neuroregenerative and neuroprotective effects of uridine/choline-enriched multinutrient dietary intervention for mild cognitive impairment: A narrative review. Neurol Ther. 2021 ;10(1):43-60. doi: 10.1007/s40120-020-00227-y

26. Derbyshire E, Obeid R. Choline, neurological development and brain function: A systematic review focusing on the first 1000 days. Nutrients. 2020;12(6):1-31. doi: 10.3390/nu12061731

27. Blusztajn JK, Slack BE, Mellott TJ. Neuroprotective actions of dietary choline. Nutrients. 2017:9(8):1-23. doi: 10.3390/nu9080815

28. Antunes M, Biala $G$. The novel object recognition memory: neurobiology, test procedure, and its modifications. Cogn Process. 2012;13(2):93-110. doi: 10.1007/s10339-011-0430-z

29. Janickova $H$, Prado VF, Prado MA, El Mestikawy $S$, Bernard $V$. Vesicular acetylcholine transporter (VAC hT) over-expression induces major modifications of striatal cholinergic interneuron morphology and function. J Neurochem. 2017;142(6):857-875. doi: $10.1111 /$ jnc. 14105

30. Friedman Jl. Cholinergic targets for cognitive enhancement in schizophrenia: focus on cholinesterase inhibitors and muscarinic agonists. Psychopharmacol. 2004;174(1):45-53. doi: 10.1007/s00213004-1794-X. 